\title{
Using Cooperative Learning to Enhance Critical Reflection
}

\author{
Meriel Huggard \\ School of Computer Science and \\ Statistics \\ Trinity College Dublin \\ Dublin 2, Ireland \\ Email: Meriel.Huggard@tcd.ie
}

\author{
Frank Boland \\ Department of Electronic and \\ Electrical Engineering \\ Trinity College Dublin \\ Dublin 2, Ireland \\ Email: Frank.Boland@tcd.ie
}

\author{
Ciarán Mc Goldrick \\ School of Computer Science and \\ Statistics \\ Trinity College Dublin \\ Dublin 2, Ireland \\ Email: Ciaran.McGoldrick@tcd.ie
}

\begin{abstract}
Over the past two decades, one of the key changes in Engineering curricula has been in the emphasis placed on the development of personal transferable skills. Employers also profess to seek these competencies when making recruiting decisions. Such skills include the ability to learn through collaboration and through meaningful critical reflection on one's own performance, both as an individual and in a group setting. However, there is still much debate on the most effective mechanisms for acquiring such skills.
\end{abstract}

Engineering students can be extremely resistant to the notion of individual or collective reflection and often find it difficult to function successfully in a group setting. This paper reports on how co-operative learning has been integrated into a largescale, practical freshman Engineering laboratory module, and explores the student experiences of being encouraged to engage in meaningful reflection. In particular, it details the presentation modalities and phenomena that influence the engineering students attitudes toward cooperative learning and reflection.

\section{INTRODUCTION}

A key element of the lifelong learning skills expected of engineering graduates is the ability to reflect critically on their professional practice. As a consequence, reflective components have become an integral element of many undergraduate engineering degree programs where students are encouraged to reflect critically on their learning. It has been shown that those who voluntarily engage in such reflective practices enhance both their writing skills and their critical thinking skills.

The authors' experience of structured reflection across six annual presentations of a key undergraduate engineering module has been somewhat different to that expressed in the literature[12], [24], [20]. It has been observed that engineering students do not engage in reflection as readily as their counterparts in the humanities and social sciences. Indeed, the students have proven quite resistant to the notion of individual or collective reflection and those that do are not inclined to engage in critical reflection on their learning.

In this paper we report on how we have sought to use cooperative learning as a way of encouraging students to engage in critical reflection within a module delivered during the second year of a cross-disciplinary Engineering programme. This module involves a hardware-software co-design project where the project description is formulated as a minimal problem domain specification, and mandates cooperative learning engagements and reflective elements as an integral, and graded, aspect of the programme syllabus.

Cooperative learning and reflective concepts are introduced to the student cohort at the commencement of the module. For most students this is their first exposure to the explicit integration of these concepts within an academic programme. Students are encouraged to work together as a group, sharing ideas and reflections on their learning. This paper explores the presentation modalities and phenomena that influence the engineering students attitudes toward cooperative learning and reflective processes.

\section{Cooperative Learning}

Recognising the changes in course content and delivery modalities, the criteria used for accrediting undergraduate degree programs have expanded to include an ability to identify, formulate and solve engineering problems, the development of the ability to function as part of a multidisciplinary team and the ability to communicate effectively [1].

Cooperative learning, which has been defined as an "instructional strategy that draws benefit from the interaction of students working in small teams to maximize their own and each other's learning"[14], forms an important element of this practice. One of the earliest reports on the impact of Cooperative Learning in engineering education classrooms was the work of Smith in 1981 [26]. Cooperative learning contrasts with individualistic learning, where students work separately to attain learning goals that are unrelated to those of other students, and competitive learning where students work in competition with each other and are ranked according to performance [25].

Cooperative Learning differs from Collaborative Learning: whereas collaborative learning has its roots in a social constructivist philosophy where learning is viewed as the the construction of knowledge within a social context and individuals form a community of learners [22]; Cooperative Learning is a "'particular set of classroom techniques that foster learner interdependence as a route to cognitive and social development" [22].

Cooperative Learning involves students working together in teams towards a common goal. To successfully achieve this goal they must learn how to communicate within their 
team, work effectively and efficiently, and make decisions as a collective rather than as individuals. They must also learn how to deal with conflict within the team and develop an an awareness and appreciation of the styles and perspectives of the individual team members. To communicate effectively team members must actively listen to each other and be willing to share information. Each team member must also learn how to provide constructive feedback to their peers and learn how to persuade others through the use of clear, logical reasoning. The team must also develop their collective decision making skills, learning how to reach a consensus on a strategy that will help them achieve their collective goals [25]. Cooperative learning approaches have been successfully used in undergraduate engineering programs [15], [18], [6] and to incentive students to pursuse Computer Science Programmes [13].

The module requires the students to take significant endto-end responsibility for the entire life cycle of the project, from conception to conclusion. The initial task is characterised through a minimum problem domain specification, with additional scaffolding and activity scope bounding arising from the provided hardware platform and the students own skillset limitations at this stage in their academic development. The project is structured around three mandatory deliverables - at weeks 4,8 and 12. These deliverables help ensure that students remain fully engaged throughout the learning process.

\section{REFLECTION}

Donald Schön's seminal work from 1983 [23] placed reflection at the heart of professional activity. Schön considered reflection as a process that occurs in two stages: when one is engaged in an activity and again once the activity has been completed. He termed these, respectively, reflection-in-action and reflection-on-action.

When reflecting-in-action an individual is seeking to develop their understanding of the current, evolving situation by drawing on their past experiences and knowledge. The individual is more likely to be "thinking on their feet" than working their way through relevant textbook theories they have encountered in the classroom.

Reflection-on-action is a post-hoc analysis that may take the form of a written or verbal evaluation. As part of this process, the person may consider their actions, both individually and in the context of the group they were operating in. While the past cannot be changed, it is believed that the individual can learn through a comparison of the original goals and objectives with the final outcomes of their work.

Schön's model was extended by Cowan [5] to include reflection-for-action. This captures the process that an individual goes through in anticipation of their learning from the task they are about to engage in. This includes reflection on their learning needs, as well as their aspirations and objectives. These will be to the forefront of the learner's mind as they engage with the task and will shape their reflecting-in-action

Cowan [5] links the process of reflection to Kolb's learning cycle [16]. He argues that the most important part of Kolb's diagram are the arrows linking the different phases of the cycle together. He posits that learners can often be cajoled to move around Kolb's cycle by being encouraged to move from experience to reflection, or from reflection to generalisation. While this view is readily embraced by educators, Cowan [5] cautions the reader that Schön's understanding of reflection is as an open-ended activity while reflection that is linked to the Kolb cycle is a bridge that leads the learner from experience to generalisation.

\section{A. Capturing the Reflective Process}

In their simplest form, diaries or journals are a chronological record of events that have occurred, together with a description of the impact of these events and the journal writer's reflections on them. The events discussed may be part of the personal life of the diary keeper or may be drawn from the world around them. More recently, written diaries and journals have often been replaced by the web log, or blog, where writers maintain an online sequence of observations or reflections that may be kept in date order. It should also be noted that journals need not be written, they may also be kept as video logs, known as vlogs. Hence, in today's world of social media, reflective journaling has moved beyond the keeping of a physical written document to a much broader setting involving the use of youtube, Google hangouts etc.

In an academic setting the nature of the journal one asks students to keep will depend on the desired learning outcomes. For example one could ask students to maintain a learning journal [21], a reflective diary [23] or a process journal [17]. In the case of a learning journal the student is maintaining a record of their learning as it occurs. This contrasts with the notion of a reflective diary where students reflect on events after they have occurred with a view to gaining an insight into their own practice and performance. The keeping of reflective diaries is not limited to the educational sphere, indeed many professionals, for example nurses [8] and teachers [9], and researchers are actively encouraged to keep such diaries. Process journals are student logs aimed at tracking their time, activity and thoughts as they work on particular problems or projects [17].

There is an inherent risk in the provision of support and guidance to students who are asked to keep journals as it may result in the undesirable forcing of the student into espousing opinions that are not really there own. This was observed in the study reported on by Brodie [4] where qualitative analysis suggested that participants were writing what they thought the facilitators wanted to hear.

\section{B. Reflection by Students of Engineering}

The nature of all STEM disciplines is such that much communication is done through technical and laboratory reports where the emphasis is on factual communication. Great emphasis is placed on the precision of the experimental description and the accurate interpretation and presentation of any data gathered. Reports are used within academia to assess the students' ability to apply their knowledge to a practical task and within the workplace they form the basis for communication between professionals e.g. between a software engineer and those responsible for the implementation of their design. In this context, the difficulties students encountered when providing conceptual and reflective data through the 
keeping of journals is not so surprising as they have been habituated to a more factual, non-reflective manner form of discourse.

This is also borne out by the literature on reflective writing where it has been noted that STEM students often experience discomfort with any form of reflective writing [10], [19], [28]. For example, in a study [4] involving over 100 firstyear, distance education engineering students it was found that when asked to produce a reflective portfolio, $82 \%$ of students produced factual, summary style reports while only $2 \%$ of the cohort engaged in deep, meaningful reflection. The study concluded that deep reflection is not a skill that comes easily to Engineering students and that if these students are to successfully engage in reflection then extensive scaffolding and support are needed.

Cowan [5], in a view shared by Heywood [11], observes that while faculty members wish their students to become reflective practitioners, many learners do not know how to reflect. The author's of this paper found their own students to be resistant to the notion of reflection, and this work documents the ways they have sought to enhance their students engagement in reflection through cooperative learning.

\section{ENVIRONMENT AND CONTEXT}

Engineering design courses seek to introduce students to all elements of the product development process so that they gain experience of what it is like to work as a professional engineer. Design is almost always something that takes place in a group or team setting. Indeed, teamwork is a key element of most professional engineering design endeavours, so it is unsurprising that it has come to play such a central role in most engineering design modules [12].

A second year undergraduate engineering design module provided the context for this study. It is a 10 credit small group, project-based module undertaken by approximately 165 students each year. At the end of their second year students taking this module must specialise into one of the following branches of engineering: civil, mechanical, electronic, computer or bio- engineering. The technologies, task and professional skills development elements of this engineering design module are explicitly chosen to be of direct benefit to all students, regardless of the specialism they choose in subsequent years.

The module runs over 12 weeks and is collaboratively offered by the Department of Electronic and Electrical Engineering (EE) and the School of Computer Science and Statistics (SCSS) in Trinity College Dublin. The module is truly multi-disciplinary with students spending two hours each week in timetabled laboratory session in both EE and SCSS i.e. 4 contact hours per week. There is also one timetabled lecture hour each week used to advise and instruct the students on technologies and concepts being encountered. The students are strongly encouraged to spend an additional twelve to fifteen hours each week working independently on the project. Laboratory support is provided by a faculty member from each of the two participating Schools, together with a teaching assistant and a team of demonstrators. The number of demonstrators allocated to the module is such that there is a student/demonstrator ratio of 10:1.

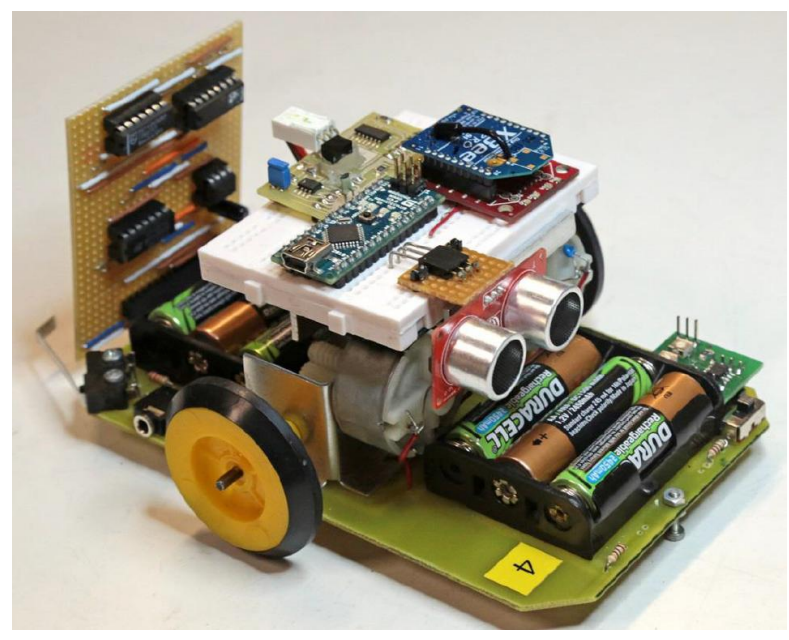

Fig. 1. TramBot

Pedagogically the module is considered to contribute significantly to a range of professional accreditation goals, both nationally and in line with Washington Accord [2] outcomes. Documented, and assessed, learning outcomes strive to develop and improve students competencies in system and software design, system integration, practical problem solving, group and peer working, project planning, critical reflection, technical documentation and presentation. The module also aims to develop students' communication, analytic, design and project management skills so that they can successfully function as professional engineers in the workplace.

\section{A. System Overview}

The high level metaphor used in presenting and describing the project task to the students is that of a tram system of the type commonly seen in European cities. Such tram systems travel on tracks laid in the city streets, incorporate points systems for track and junction changes, have remote signalling systems and communications capabilities, and are electrically powered. This engineering design module requires students to implement a full emulation of such a tram system in the laboratory. Students are provided with a minimum problem domain specification for the capabilities of their TramBot(s); compatible with the goals and principles of the ConceiveDesign-Implement-Operate (CDIO) Initiative [27].

The high level environment comprises a track with a high contrast black line for the tram to follow, IR gantries above the track at key locations, wireless communication between devices and a PC to serve as the control station. The track has both an outer and inner "express" loop and the TramBot is a small, two-motor chassis with wireless communications, line following, gantry detection and ultrasonic range detection capabilities (see Figures 1). The primary components onboard the TramBot are an Arduino Nano microcontroller [3], an XBee [7] wireless communications device, a "Gantry" IR detection circuit and ultrasonic ranging capabilities. The chassis hardware platform is updated and extended annually to invalidate designs and solutions from the preceding years (see Figure 2).

Each group is provided with a TramBot at the outset of the activity, and two test tracks with fixed gantries are available 


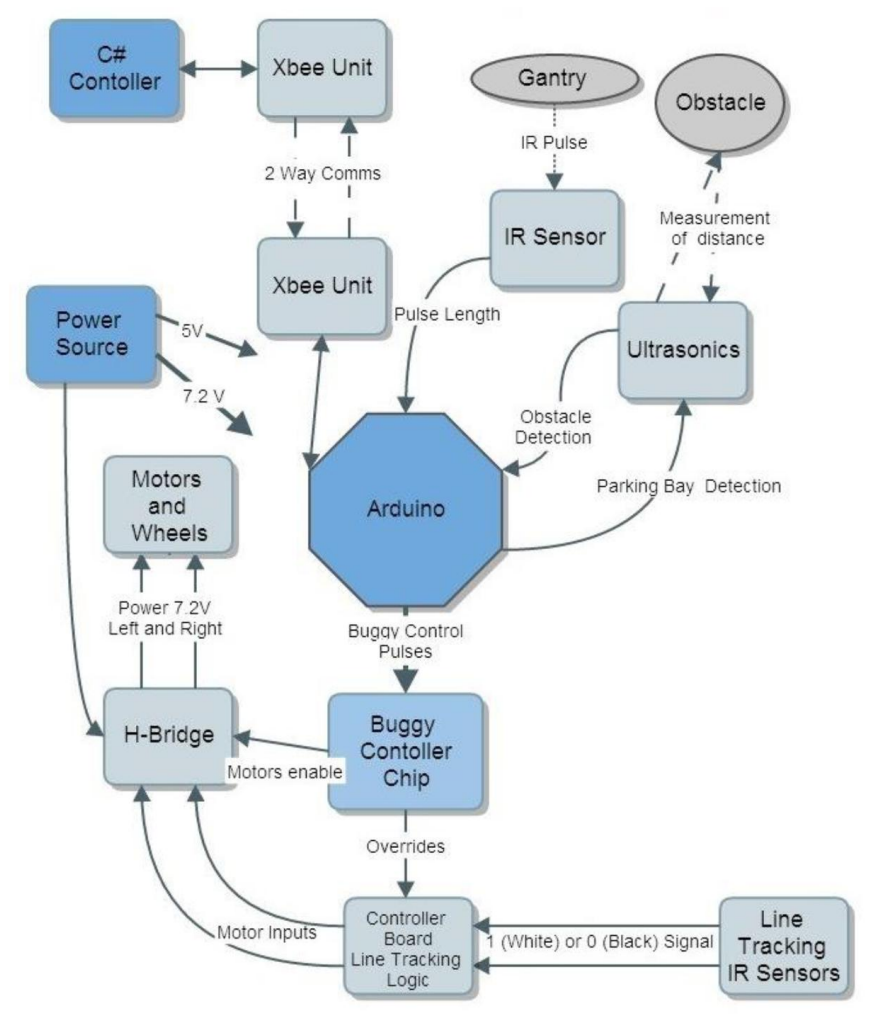

Fig. 2. TramBot Interactions and Data Flows

for ongoing test and development. The students are responsible for all aspects of the design, implementation and realisation of their solutions, subject only to the specification of the assessment modalities provided by the module staff at the outset, and the constraints of the provided TramBot hardware. As the emphasis is clearly on producing the best solution to an Engineering challenge, no specific technologies, languages or solution paths are otherwise mandated. Thus the emphasis on collaborative peer engagement is clearly established at the outset of the activities.

\section{B. Support Structures}

The enabling and facilitation of cooperative learning is directly vested in the skill and sensitivity of the demonstrators and module staff. Considerable effort must be invested in training and guiding the demonstrator team in the early formative years of the module. They are individually selected from the pool of available postgraduate demonstrators, with each annual intake of "new recruits" being guided and trained by the more experienced team members. A strong team dynamic is fostered that extends from module preparation through to demonstrating and into interviewing, assessment and final grading. A key activity for the faculty members is in ensuring that the demonstrator team are coherent, consistent and professional in all their dealings with the students.
The module credo sees almost every group proceed along different paths at different progression rates, while posing different challenges and solutions. This is at odds with more traditional demonstrator engagement metaphors, which favour uniformity and conformity in tasks and solutions in order to reduce workload and time commitments.

In order to encourage student engagement at all levels, assignment grading is effected using both traditional individual grading and collaborative group grading modalities. The group grading strategies help ensure consistency within and across demonstrator grading activities, whilst contributing significantly to their research and professional training through building assessment capacity and competencies in the demonstrators themselves.

Direct interaction with each group, and each individual student, is a feature of every laboratory session. Students are cleared advised at the outset of the absolute necessity to fully understand every aspect of the project tasks - from strategy through hardware and software design to the final demonstration and interview. Noting that students are generally extrinsically motivated, the module staff discuss and quiz the students on what they are doing, how they are doing it, why they are doing it and to what effect. This constant challenging of the students to articulate the evolution of their thinking and understanding of the problem scenario is one of the key ways in which they are led towards deeper, more critical reflection on their learning. This deeper reflection is further encouraged through the assessment and grading mechanisms employed, as these explicitly assess this students' articulation of their understanding of the challenge.

\section{ASSESSMENT DRIVEN COOPERATIVE AND REFLECTIVE ACTIVITIES}

As might be expected module assessment is complex, being both multi-faceted and multi-dimensional. Quantification of the student experience, and their role in shaping the learning environment, is instrumental to assessing module outcomes. The assessment strategies are carefully chosen so as to encourage the students towards full participation in their allotted groups and regular reflection upon a wide range of aspects of their performance, both individually and collectively

Evaluation and assessment of student performance and achievement occurs through informal laboratory engagement, formal graded deliverables, an individual quiz and a final practical system demonstration and interview for each group. Feedback from each student on their experience of peer group engagement and learning, and their sense of the strengths and weaknesses of their engagement, is explicitly mandated within each deliverable.

In the early deliverables for the module, the groups identify the skillsets that the individual group members possess, distribute task responsibilities and reporting roles across the group, and postulate as to how the project will successfully evolve based on their early insights. This relates strongly to Cowan's [5] concept of reflection-for-action.

A subsequent interim report incorporates updates to the individual roles assigned within the group, the individual and group responsibilities for the delivery of the completed 
TramBot and the group's agreed workplans. This interim report also begins the process of reflection-on-action [23] and requires a reflective synopsis on the group dynamic and peer engagement. The demonstrator team are carefully briefed to ensure they can scaffold these reflection activities - indeed this briefing itself often takes the form of a group reflectionon-action where those who demonstrated on the module in previous years verbally share their experiences and discuss successful strategies.

The final student evaluation is a multi-faceted activity. Students undertake an individual, timed quiz that spans all aspects of the project. The question bank is large, with questions randomly assigned within categories. The existence of this individual assessment is used to ensure that students engage with all aspects of the project throughout the 12 weeks that the module runs for. In the early stages of the module, the existence of this assessment is used as a way to disincentive groups from adopting silo-based strategies that provide only limited opportunities for the collaborative learning environment the module seeks to foster.

Groups are required to perform a practical task demonstration at the end of the module. The assessed behaviours are defined at the outset of the module, so the goals each group set themselves require a sufficient level of application throughout in order to be attained. Most groups strive towards "gold" standard but some compromise and aim for "bronze" at an early stage in the project. The formal declaration of the outcome the group believes they can demonstrate occurs immediately in advance of the activation of the group's TramBot on demo day. As their work on the module progresses the existence of this list provides a talking point that can be used to encourage students to reflect, both individually and collectively, on a wide variety of factors e.g. their individual progress, the progress of the group as a whole, the functioning of the group and their role within it. Students who are unhappy with their own performance or that of their group are encouraged to be proactive about attempting to change their own behaviour or that of the group.

During the final practical demonstration discrepancies between the actual and nominated performance must be explained, the grading of this element of the module is tied to the groups ability to critically analyse these performance discrepancies. A short twenty minute group interview then takes place where all aspects of the system architecture, implementation and actualisation are explored and evaluated with all group members.

Thereafter each group submits their final report in the form of a self-contained system design, implementation and validation document. At this point they also finalise their personal feedback and reflection, and expound upon their peer engagement and cooperative learning experiences and insights.

The top five systems, as determined from their performance at the final demonstration, then compete for a set of sponsored cash prizes. Each group makes a short video about the innovative features of the design and operation of their TramBot and these are then uploaded to one of the University's dedicated video channels. Public viewing, voting and feedback takes place over six weeks, with associated social media commentary. An independent assessment panel, comprising representatives of some of our multinational sponsors, meet and critically assess each of the five systems, taking account of the impact and awareness of the Programme each video generated in the wider community, and agree on a final ranking of the TramBots.

As can be seen from the above discussion, the apparent complexity of the assessment suite masks a variety of direct and indirect approaches to managing student behaviour and engagement. The module has a high credit value, cannot be repeated or supplemented in the same year, and is the student's first significant CDIO [27] activity. Thus it is critical that the module transition students from a fixed mental attitude where the emphasis is on the prescriptive, directive, rote individual completion of tasks towards a more creative, collaborative, outcome oriented mindset and approach.

For many students their initial attempts to reflect on their performance were mainly descriptive in that they focussed on a narrative history of the week's events e.g. on stating what laboratory sessions and lectures they had attended, the topics encountered and the related activities they engaged in on a given day. The data provided in terms of the activities undertaken was often quite technically detailed; in marked contrast to the length and nature of the commentary provided when the students were asked to reflect on how these activities drew on their prior knowledge and experience. The students seemed to be accustomed to partitioning their knowledge into specific areas e.g. they felt that topics they had encountered in physics modules would only be of relevance in future physics modules. As the Trambot module cut across a number of the disciplines that they encountered, they found it difficult to evaluate and reflect on how their engagement with the project built on their prior knowledge and life skills.

Since students were specifically asked to focus on the nature of their work with the group, and to look at the factors that contributed to its success, this provided opportunities for those assessing to explore how the students understanding of what it means to function as part of a team grew and evolved during the module. As they engaged in regular reflection over the course of the module the students were encouraged to look beyond its confines and to the broader world of their studies and their development as a professional engineer.

\section{DISCUSSION}

In this section we use the students' own words to illustrate their reflections on their understanding of cooperative learning, team work and the nature of teams. The close integration of reflection into all stages of the TramBot project meant that it was not an activity to be carried out in isolation, but rather an essential part of the experience. The students' reflections demonstrate they have developed an appreciation of many of the key elements that are essential for a group to work well and be successful in achieving their desired objectives.

The group reflection below illustrates the students' awareness of the need for synergy amongst the group members in order to achieve their shared objective:

Group A:"It was found that the team worked better together and had an easier time integrating the different components and programs, as well as debugging, when everyone on the team had a working 
knowledge of every aspect of the project. The whole team learned about the importance of completing the tasks assigned to them, as one member not pulling their weight meant that the whole team fell behind. In any group, disputes are unavoidable, but our group learned to handle these disputes in a mature and efficient manner."

Another essential trait of successful group performance is that the team members must be committed to achieving their objective. This is noted in the following group reflection.

Group B:"The final top strength in our team was dedication. We met up on a regular basis to try to ensure we fulfilled our deadlines. From the beginning we aimed to achieve the gold challenge and we succeeded due to hard work and dedication. If we fell behind schedule we would put in extra work and hours to ensure we caught up as soon as possible."

In the following reflections the groups dwell on the importance of careful time management by both individuals within the group and by the group as a collective:

Group C:"Time management and work division was also a huge tasks that we overcame. Our group was largely successful in the even distribution of work amongst our members. However, due to complacency, over the course of our project, on occasion, certain sub tasks were taken on by members whom they were not assigned to originally. This was not a major problem, as the forthcoming work was distributed in a fair manner according to the extra work undertaken by certain members of the group."

Group D:"Time keeping was a major issue we had for the duration of this project. Although we eventually met all marked deadlines, we did not strictly follow the project plan, which is a key issue that led to us not making our goals. It was very hectic the days things were due causing unnecessary friction within the group. If we had kept to our schedule more tightly, there would not have been any problems when facing these deadlines and we would likely have completed the Silver and Gold challenges."

Even though they may not have dealt with problems in a manner they were happy with they had reflected on the root causes and gained valuable future insight into peer assessment and group dynamics. In the quotations below the groups reflect on the importance of group adaptability, particularly when faced with changing circumstances and unforeseen events:

Group E:"We hit a wall at around week eight. Lack of progress and the countdown to week twelve caused a huge panic in the group. This prevented us from working together and calmly engaging in solving any problems. At this point we needed to take a step back so we could reassess the situation. Remaining calm at the most testing points would benefit our progress."

Group F:“'One the team's gravest errors was unrealistic planning and was possibly the main reason why
Gold standard was not achieved. Allow for errors and unproductive lab sessions where certain tasks were not fully complete. Some lab sessions could be spent fixing an error which never caused difficulty before, and these delays in progress must be accounted for."

Group G:"The second problem that the team faced was failure of the demonstration on the day, despite it working in practise. Although the marks were lost for not fully achieving the Silver Challenge during the demonstration, the group had prepared for this circumstance. A back up Bronze Challenge code was ready to be demonstrated. The Silver code was also well commented and understood by each team member, and the group were able to demonstrate their understanding of the Silver Challenge during the group interview."

The following groups recognised that teams that perform well need to avoid complacency through constantly challenging themselves:

Group H:"The group may have become too comfortable with certain deadlines. This became very apparent when looking back at the initial few weeks of the project. The group was meeting the deadlines being set out in the initial three or four computer and hardware labs. However, the group could have pushed on during this period allowing the group to work ahead of schedule, and giving the group more time in the closing weeks of the project to help to progress towards the gold standard."

Group I:"The team should have kept the gold standard open as an option for longer. By eliminating this as a viable option perhaps too early in the project the group may have became overly content with progress towards bronze standard. In keeping gold standard open as an option this may have pushed the group on."

Many groups attributed their success to good communication skills:

Group J:“One of our team's key strengths was communication. Our team used the facilities available to us to stay in contact very well. Utilising phones, facebook and email we were able to stay in touch at practically any time. This meant a fast response to any question or query to team members. We also used facilities like Google drive, blackboard, SVN and email to share information with each other. A good example of this was during the write up of our Interim report. Many members of the group were scattered around the country during the midterm break which meant group meetings weren't possible. We overcame this issue through our varied communication network and completed the Interim Report ahead of schedule. Our communication network meant that any code, ideas or report drafts could be distributed around the group quickly to be proofed and any necessary alterations made. We also had regular group meetings to discuss the plans for the upcoming week." 
Group K:"Cloud Computing All of the team's work was shared using Google Drive. Not only did this act as a back-up of all the groups' progress, but allowed the group to access and modify all aspects of each other's work. Each week, the group secretary uploads all the folder, codes, files and assignments into the designated folder. In the "Log Activity" folder, each team member updated their weekly work while in the "Gantt Chart" spreadsheet, weekly targets and goals were monitored and updated. These interactive documents not only enable each member of the group to be up to date on each other's work, but also help them to visualize the team's overall weekly progress."

The connection between preparation and planning, and the attainment of the groups' objective is highlighted in the following reflections:

Group L:“As a group, we tended to jump in to creating a solution to a problem without first properly defining either the problem or the solution we were trying to implement. Had we made more frequent and detailed use of block diagrams and other such organisational tools, we would have found it easier to assign specific and discrete tasks to each member of the team and to generate solutions that were simpler and easier to understand from the start."

Group M:"More preparation for group interview: The last thing we would have done differently would be to prepare for the interview a lot more than we did. We were so focused on achieving the gold challenge during the last week, so we didnt have enough time to prepare for our interview and we felt we could have improved significantly if we had spent some more time on our preparation."

Group N:"Our SVN repository was not kept as tidy as possible there were multiple files with names that did not particularly clarify their content or how up to date they were. This led to us having to create a separate folder for files for the test to ensure we did not use out of date files in the final test. We should have been much clearer about our naming system and deleted any files which no longer served a purpose. This would have made it much easier to see at a glance what the important files were and when they had last been updated."

Some of the individual reflections, show that even those students who do not intend to pursue careers in Electronic or Computer Scientists, have gained an appreciation of the need for the team to work together towards there common objective of completing the project:

Student 1:"This was the most interesting project I've ever done and I really enjoyed working with lots of different aspects of engineering (Electronics and Computers) and making them all come together. I think this project cemented my idea of becoming a civil engineer, because at times the stress and frustration from the simple coding mistakes drove me and the team crazy. But we learned that each member of the group was better at certain things and we benefited by utilising that. And because the team worked so well together, helping each other with problems and the work load was evenly distributed, we managed to successfully complete the project."

The student quoted below, not only reflects on how his own understanding has evolved, he also appreciates that a successful group needs to operate collectively:

Student 2:"Having completed this project, I now have a better understanding of the different kind of situations engineers could be faced with in their profession. I also found that combining two aspects of engineering in one project was a very interesting challenge as it showed me how the hardware and software parts were closely linked: as in how the code we wrote used the components on the Trambot to do tasks i.e. to detect gantries and move around the track. Collectively, I thought the group developed some very good group skills when it came to task division but also when it came to making decisions as a whole group."

The quotations given above show that, through reflection, many groups were able to identify traits that would make them capable of operating at a high performance level. Moreover, they show that, in their reflection-on-action, the students were able to critically assess their own performance and identify reasons why their own group had failed to achieve the desired standard. While the failure to successfully complete assigned tasks can have immediate ramifications in the workplace, failure to identify, acknowledge and take ownership for such issues at the earliest opportunity is potentially more damaging for the company and all its employees. In an academic setting such learning opportunities are an essential part of the student professional and ethical development.

\section{CONCLUSION}

This paper has explored the use of cooperative learning as a mechanism for encouraging undergraduate engineering students to engage in meaningful, critical reflection. The delivery, assessment and grading modalities have been fine tuned over the past six presentations of the module, so that they are fully aligned with its objectives. The reported student experiences demonstrate that they have developed considerable awareness of the traits common to highly successful groups, also illustrate the capacity for reflection they have developed during the course of the module.

\section{REFERENCES}

[1] ABET. Criteria for Accrediting Engineering Programs. ABET Inc., Baltimore, MD., USA, 2011.

[2] Washington Accord, 2012. [Online]. Available:http://www. washingtonaccord.org/.

[3] Arduino Nano, 2014. [Online]. Available:http://www.arduino.cc.

[4] L. Brodie. Reflective writing by distance education students in an engineering problem based learning course. Australasian Journal of Engineering Education, 13(2):31-40, 2007.

[5] J. Cowan. On becoming an innovative university teacher: reflection in action. Society for Research into Higher Education and Open University Press imprint. Open University Press, 2006. 
[6] I. de los Ros, A. Cazorla, J. M. Daz-Puente, and J. L. Yage. Project based learning in engineering higher education: two decades of teaching competences in real environments. Procedia - Social and Behavioral Sciences, 2(2):1368 - 1378, 2010. Innovation and Creativity in Education.

[7] XBee. Digi International Inc., 2014. [Online]. Available:http://www. digi.com/xbee/.

[8] T. Durgahee. Reflective Practice: nursing ethics through story telling. Nursing Ethics, 4(2):135-146, 1997.

[9] D. Francis. The reflective journal: A window to preservice teachers' practical knowledge. Teaching and Teacher Education, 11(3):229-241, 1995.

[10] J. Hamilton-Jones and T. Svane. Developing research using reflective diaries. In Frontiers in Education, 2003. FIE 2003 33rd Annual, volume 1, pages T3A-14-19 Vol.1, 2003.

[11] J. Heywood. Private Communication, Mar 2014.

[12] P. L. Hirsch and A. F. McKenna. Using reflection to promote teamwork understanding in engineering design education. International Journal of Engineering Education, 24(2):377-385, 2008-03-01T00:00:00.

[13] M. Huggard and C. McGoldrick. Incentivising students to pursue computer science programmes. In Frontiers in Education Conference, 36th Annual, pages 3-8, Oct 2006.

[14] D. Johnson, R. Johnson, and E. Holubec. Circles of learning: cooperation in the classroom. Interaction Book Co., 1990.

[15] P. Johnson. Problem-based, cooperative learning in the engineering classroom. Journal of Professional Issues in Engineering Education and Practice, 125(1):8-11, 1999.

[16] D. Kolb. Experiential Learning. Prentice Hall, 1984.

[17] G. Lewandowski. Using Process Journals to Gain Qualitative Understanding of Beginning Programmers. Journal of Computing Sciences in Colleges, 19(1):299-310, 2003.
[18] C. McGoldrick and M. Huggard. Peer learning with lego mindstorms. In Frontiers in Education, 2004. FIE 2004. 34th Annual, pages S2F 24-9 Vol. 3, Oct. 2004.

[19] U. Melin Emilsson and B. Lilje. Training social competence in engineering education: necessary, possible or not even desirable? An explorative study from a surveying education programme. European Journal of Engineering Education, 33(3):259-269, 2008.

[20] F. Mistree, J. Panchal, D. Schaefer, J. K. Allen, S. Haroon, and Z. Siddique. Personalized engineering education for the twenty-first century. In M. Gosper and D. Ifenthaler, editors, Curriculum Models for the 21st Century, pages 91-111. Springer New York, 2014.

[21] J. Moon. Learning Journals: A Handbook for Academics, Students and Professional Development. Taylor \& Francis, 2006.

[22] R. L. Oxford. Cooperative Learning, Collaborative Learning, and Interaction: Three Communicative Strands in the Language Classroom. The Modern Language Journal, 81(4):443-456, 1997.

[23] D. Schön. The reflective practitioner: how professionals think in action Basic Books, 1983.

[24] A. Shekar. Active learning and reflection in product development engineering education. European Journal of Engineering Education, 32(2): 125 - 133, 2007.

[25] K. Smith. Cooperative learning: Lessons and insights from thirty years of championing a research-based innovative practice. In Frontiers in Education Conference (FIE), 2011, pages T3E-1 -T3E-7, Oct. 2011.

[26] K. Smith, D. Johnson, and R. Johnson. The Use of Cooperative Learning Groups in Engineering Education. In Frontiers in Education Conference (FIE), 1981, Rapid City, SD, Washington, Oct. 1981.

[27] The CDIO Initiative, 2014. [Online]. Available:http://www.cdio.org/.

[28] M. R. Wallen and A. S. Pandit. Encouraging undergraduate engineering students towards civic engagement. European Journal of Engineering Education, 34(2):141-148, 2009. 